\title{
Electroencephalogram in Childhood Neurological Disorders
}

\author{
Wael Hayel Khreisat , Pediatric Neurologist \\ Queen Rania al Abdullah Hospital for Children \\ King Hussein Medical Center \\ Royal Medical Services \\ Amman. Jordan
}

\begin{abstract}
Aim of the study: The present study was done to obtain a baseline for clinical indications of EEG in children and to evaluate the Electroencephalography (EEG) findings in children with various acute, chronic CNS disorders and non epileptic events.
\end{abstract}

Patients and methods: The Electroencephalography (EEG) records of 250 patients were studied, which was done at neurophysiology departments of Queen Rania AL-Abdullah Hospital for children in Jordan. For each patient underwent EEG record the following data were recorded, age, sex, source of referral ( in patient department or out patient ), reason for Electroencephalography (EEG), diagnostic impressions and clinical presentation, the result of the EEG examinations and clinical correlation between the seizure type and EEG finding .

Results: Males slightly outnumbered females: 55\% males. The majority of cases sent for EEG fell between 6-12 years, Total of $63.2 \%$ of all referrals for EEG were from outpatient clinic while in patients account for $36.8 \%$. pediatric neurology department referrals being highest $28.8 \%$, the majority of diagnosis at referral were suspected epilepsy (80\%), epileptiform EEG abnormalities was detected in ( $32 \%$ ), Over all $64 \%$ the EEG records were normal, All EEG records of children with syncope, headache were normal .

Conclusion and recommendation: We conclude that there are many unnecessary routine EEG recordings in children; Investigation of epilepsy and acute encephalopathies appear to be the most valuable indications for routine pediatric EEG. EEG can help in classified of the seizure, finding a way to reduce EEG requests is request

Keywords : Epilepsy; Electroencephalography; paroxysmal event

\section{Introduction}

A huge number of publications have documented the type and frequency of Electroencephalography (EEG) abnormalities in many different childhood disorders (Goldensohn, 1997). EEG is a very important in investigating children with various neurological disorders, particularly epilepsy. The EEG is also a sensitive marker of diffuse cortical dysfunction as seen in toxic, metabolic, or hypoxic encephalopathies (Saunders and Westmoreland, 1997 ).
Although the diagnosis of seizures and epileptic syndromes is primarily clinical, EEG often provides supportive evidence and helps in seizure classification (Sundaram et al., 1999).

Many episodic events may simulate epilepsy including breath holding spells, syncope, tics, migraine related phenomena (e.g. benign paroxysmal vertigo), and psychogenic seizures (Barron, 1991 ). These events associated with normal neurological examination and interictal EEG, however, although EEG is requested, a 
complete event description accurately identifies the nature of these events in most cases (Wyllie et al. , 1991 ).

Practice parameters endorsed by the American academy of pediatrics, recommended use of EEG after non febrile seizure in children, as standard of care (Blume and Kaibara , 1999) . However, non neurologist physicians differ in their expertise in clinically identifying seizures and many have tendency to exclude almost any paroxysmal events such as syncope, tics or staring spells in attention deficit hyperactivity disorders in their definition of seizures (Donat and Wright , 1990 ) more over EEG is now easily accessible because of its safety and low cost-benefit ratio (Metrick et al. , 1991), this has led to an indiscriminate overuse of EEG in clinical practice decreasing the yield of the clinical useful information In one study, up to $40 \%$ of EEG requests were considered to be unnecessary (Nicolaides et al. , 1995 )

The present study was done to obtain a baseline for clinical indications of EEG in children, who are of regular visit at pediatric departments of Queen Rania AL-Abdullah Hospital for children to evaluate the EEG findings in children with various acute and chronic CNS disorders, to asses relationship between the clinical indication and EEG abnormalities and assess the predictability of a normal EEG result.

\section{Patients and methods}

This a retrospective study, included 250 consecutive EEG recorded, which was requested by pediatrician, child neurologist, and family doctors. All EEGs were performed in neurophysiology unite of Queen Ranai Abdullah Hospital for children at Jordan.

For each patient underwent EEG record the following data were recorded, age, sex, source of referral ( in patient department or out patient ), reason for EEG , diagnostic impressions and clinical presentation, the result of the EEG examinations and clinical correlation between the seizure type and EE finding .

All EEGs studies were recorded digitally and reviewed according to standard clinical practices at the clinical neurophysiology laboratory of Queen Rania Abdullah Hospital for children. All studies utilized both bipolar and average referential montages performed by using a 8-16 channel digital recording with electrodes placed according to the international 10-20 systems. Routine EEG consisted of a normal recording of 20-30 minutes, including three minutes hyperventilation and intermittent photic stimulation at various frequencies.

The EEGs abnormalities were classified: focal or multifocal spike waves, generalized epileptiform discharges , focal or diffuse background disturbance, burst suppression pattern and spindle coma

Requests for EEG are a written requisition, based on the indications as description for events, the clinical indication responsible for requesting the EEG was one of the following categories: (1) established epilepsy; (2) nonepileptic paroxysmal events (e.g. migraine, syncope, breath holding spells); (3) acute CNS disorders (e.g. toxic metabolic, infectious, or hypoxic encephalopathy); and (4) non-epileptic chronic CNS disorders (e.g. mental retardation, autism, attention disorder).

In patients with both clinical and EEG evidence of epilepsy, seizure were classified according to international classification of the the International League Against Epilepsy (ILAE ) ( Noachtar et al. , 1999 )

At the end of each assignment, the EEG requisitions were reviewed for clinical correlation. At this stage the relationship between the clinical indication and EEG result was recorded for further study.

\section{Results}

A total number of 250 recorded EEG were studied. Among these, males slightly outnumbered females: 55\% males. The age ranged between four months and 14 years, patients under 10 years constituted more than 50 $\%$ of the study populations. The majority of cases are between 6-12 years. The ages distribution of all patients is as shown in Table I

Total of $63.2 \%$ of all referrals for EEG were from outpatient clinic while in patients account for $36.8 \%$. There was a broad spread of referral from major specialists of pediatrics, psychiatry , neurosurgery and intensive care unit, pediatric neurology department referrals being highest 
$28.8 \%$, The source of referrals of patients for EEG are as shown in table II .

The majority of diagnosis at referral were suspected epilepsy (80\%), epileptiform EEG abnormalities was detected in (32\%) The diagnosis at referral are shown in the figure 1.

The seizure types in patients with a history of epileptic seizures and epileptiform EEG abnormalities are shown in the table III, the majority of the seizures were partial seizure with secondary generalization. Primary generalized seizures were uncommon, with petit mal absences a counting for only $9.3 \%$ of the total seizures , the majority of patients with epilepsy were referred for EEG to confirm the diagnosis ; $5.5 \%$ were referred because of poor seizure controlled and $1,6 \%$ referred to exclude space occupied .

Attention deficit hyperactivity disorders $9,1 \%$, learning disabilities $2 \%$, tic disorders and $1.1 \%$ others (mental retarded, head trauma, behavior disorders , metabolic , etc )

Over all 64 the EEG records were normal , 14.4 $\%$ focal or multi focal spikes, generalized epileptic activity $11.2 \%$, while others ( spindle coma , burst suppression , hypsarrythemia ) forming $2.8 \%$ ( Table IV ) (samples figure II,III)

Epileptic activity was rarely found in the non epileptic group of patients with non epileptic condition there was no epileptic activity. All EEG records of children with syncope, headaches were normal.

\section{Discussion}

This study highlights certain important issues in the utility of EEG in children. The EEG was very helpful in diagnosing epileptic syndrome and in seizure classification. The EEGs of some patients with epilepsy also revealed completely unexpected findings that strongly influenced their management. This highlights the very important role of EEG in patients with epilepsy.

The age distribution of patients with this study, showed patients under 8 years constituting $50 \%$ of the study population probably reflects that majority of cases with epilepsy, belong to this age group, the progressive increase in the proportion of patients with normal EEG with increasing age group is well known in patients with epilepsy (Falope et al ., 1993 , Marsan and Zivin ,1970) who make up of some $65 \%$ of our patients .

Tow thirds of our referrals were in out patients, similar to findings for neurophysiology investigations in developed countries (Binnie, 1994) .

Most children (98\%) with non-epileptic paroxysmal events (e.g. migraine, syncope, and breath holding spells) had a normal EEG. Other investigators found normal EEGs in up to $87.5 \%$ of adults with non- epileptic paroxysmal events (headache, syncope, and vertigo) (Airoldi et al. , 1999) .

We think that there are some special reasons that lead to EEG requests for, non epileptic disorders. First, to exclude epilepsy. It is well known that a small percent of children without any neurologic disorder have EEG abnormalities (Petersen and Eeg , 1968 ), as well children with epilepsy may not show interictal EEG abnormalities. (Camfield et al. , 1995 ) second reason may be a lack of understanding of the limits of EEG recording and interpretation. (Airoldi et $\boldsymbol{a l}$. , 1999 ). . The EEG is therefore not helpful in these children and a complete event description will accurately identify the nature of these events in most cases rather than EEG (Camfield et al ., 1995 ). More than $10 \%$ of normal people may have non-specific EEG abnormalities and approximately $1 \%$ may have 'epileptiform paroxysmal activity' without seizures (Niedermeyer, 1999). The prevalence of these abnormalities is higher in children, with $2-4 \%$ having functional spike discharges. It is of interest that an attempt to provide guidelines to physicians for appropriate EEG use may not alter their practice (Van Walraven and Naylor , 1998).

It was reviewed EEGs in people with epilepsy, $30 \%$ of patients, their EEGs contained epileptiform discharges which is closed to our study (Ajmone and Zivin , 1970 ). Taken together, these studies suggest an $80 \%$ chance of showing epileptiform activity in a first wakeand- sleep EEG in people with epilepsy. Provided there is no other evidence of cerebral disease, epileptiform activity is rare in those who are and will remain free of epilepsy. It is therefore the practice to offer referring doctors the ability to order a combined routine and 
sleep EEG as the first investigation in patients with epilepsy, This policy reduces costs and inconvenience to patients in an epilepsy service but is inappropriate for patients with a low chance of having epilepsy, and therefore requires some discrimination by the doctors (Binnie , 1994 ) .

The EEG has many uses in epilepsy but may also be abused. The situations in which the EEG can contribute to the diagnosis of epilepsy are rare. Once the diagnosis of epilepsy is established, the EEG is probably the most important investigation in helping to define the type of epilepsy, the prognosis, and the initial approach to therapy (Adrian et al. , 2000 ). In partial seizures, EEG is the investigation of first choice for localization and is an important part of the work-up for the few patients who come to epilepsy surgery (Dalby , 1969 )

Some investigators found that $\mathrm{HV}$ and photic stimulation contributed little to the final EEG report (Airoldi , 1994 ). Many of our children with focal or generalized epileptiform discharges had spike activation on photic or HV (19\%). HV was particularly helpful in children with absence epilepsy, which is consistent with the findings of other investigators (Small, 1993 ).
In a recent review of EEG studies of children with ADHD, it was concluded that between $30 \%$ and $60 \%$ of such children showed abnormal EEG findings, including generalized and/or intermittent slowing. Further, there was some evidence that the EEG abnormalities decreased with age, with contradictory reports of poor or no correlation between abnormal EEGs and treatment response (Phillips et al. , 1993 )

However, some of ADHD children was found to have an abnormal EEG in a recent study in which the authors conclude that routine EEG screening is of limited value in childhood behavior problems (Williams et al., 2001 ).

\section{Conclusion and recommendations;}

We conclude that there are many unnecessary routine EEG recordings in children. Investigation of epilepsy and acute encephalopathies appear to be the most valuable indications for routine pediatric EEG. Finding a way to reduce EEG requests should be done since EEG has been requested, the effect of cancelling the test may be to undermine the patient's confidence in their physician. Physician education seems more palatable .

$\underline{\text { Table I : age range in all patients compare with normal Electroencephalography }}$

\begin{tabular}{|c|lcc|cc|}
\hline Age & \multicolumn{2}{|c|}{ Number $\quad(\%)$} & \multicolumn{2}{c|}{ Normal EEG (\%) } \\
\hline$>$ 1 years & 38 & $(15.2)$ & 26 & $(10.4)$ \\
\hline $1-3$ years & 48 & $(19.2)$ & 24 & $(9.6)$ \\
\hline $3-6$ y & 42 & $(16.8)$ & 29 & $(11.6)$ \\
\hline $6-9$ & 52 & $(20.8)$ & 31 & $(12.4)$ \\
\hline $9-12$ & 38 & $(15.2)$ & 23 & $(9.2)$ \\
\hline $12-14$ & 32 & $(12.8)$ & 27 & $(10.8)$ \\
\hline Total & 250 & $(100)$ & 160 & $(64)$ \\
\hline
\end{tabular}


Table II: Source of patients referral for Electroencephalography

\begin{tabular}{|c|c|c|c|c|}
\hline Department & In patient $\%$ & Out patients $\%$ & Total & $\%$ \\
\hline Neurology & (10) & $47 \quad(18.8)$ & 72 & $(28.8)$ \\
\hline Neurosurgeon & $(7.5)$ & $(8)$ & 38 & $(15.2)$ \\
\hline $\mathrm{Icu}$ & $(6.8)$ & - & 17 & $(6.8)$ \\
\hline Emergency & - & $(12.8)$ & 32 & $(12.8)$ \\
\hline Psychiatric & $(2.4)$ & $(6.8)$ & 23 & $(9.2)$ \\
\hline General pediatrician & $(2.4)$ & $(4.8)$ & 18 & $(7.2)$ \\
\hline Others & $(8)$ & $(12)$ & 50 & $(20)$ \\
\hline Total & $(36.2)$ & $(63.2)$ & 250 & (100) \\
\hline
\end{tabular}

Table I11 : Clinical and Electroencephalography classification in patients with seizures confirmed by Electroencephalography

\begin{tabular}{|l|l|l|}
\hline Seizure type & No of patients & $\%$ \\
\hline Primary generalized & & \\
Tonic -clonic & 12 & 18.6 \\
Petil mal & 6 & 9.3 \\
Myoclonic & 10 & 15.6 \\
\hline Partial & & \\
Simple & 18 & 28.2 \\
Complex partial & 14 & 21.9 \\
With secondary generalization & 4 & 6.3 \\
\hline Total & 64 & 32 \\
\hline
\end{tabular}

Table IV : Electroencephalography results

\begin{tabular}{|l|lc|}
\hline EEG FINDING & No & $(\%)$ \\
& & \\
\hline normal & 160 & $(64)$ \\
\hline Focal or multifocal spikes & 36 & $(14.4)$ \\
\hline Generalized epileptic activity & 28 & $(11.2)$ \\
\hline Focal background disturbance & 8 & $(3.2)$ \\
\hline Diffuse background disturbance & 11 & $(4.4)$ \\
\hline Others & 7 & $(2.8)$ \\
\hline Total & 250 & $(100)$ \\
\hline
\end{tabular}


Electroencephalogram in......

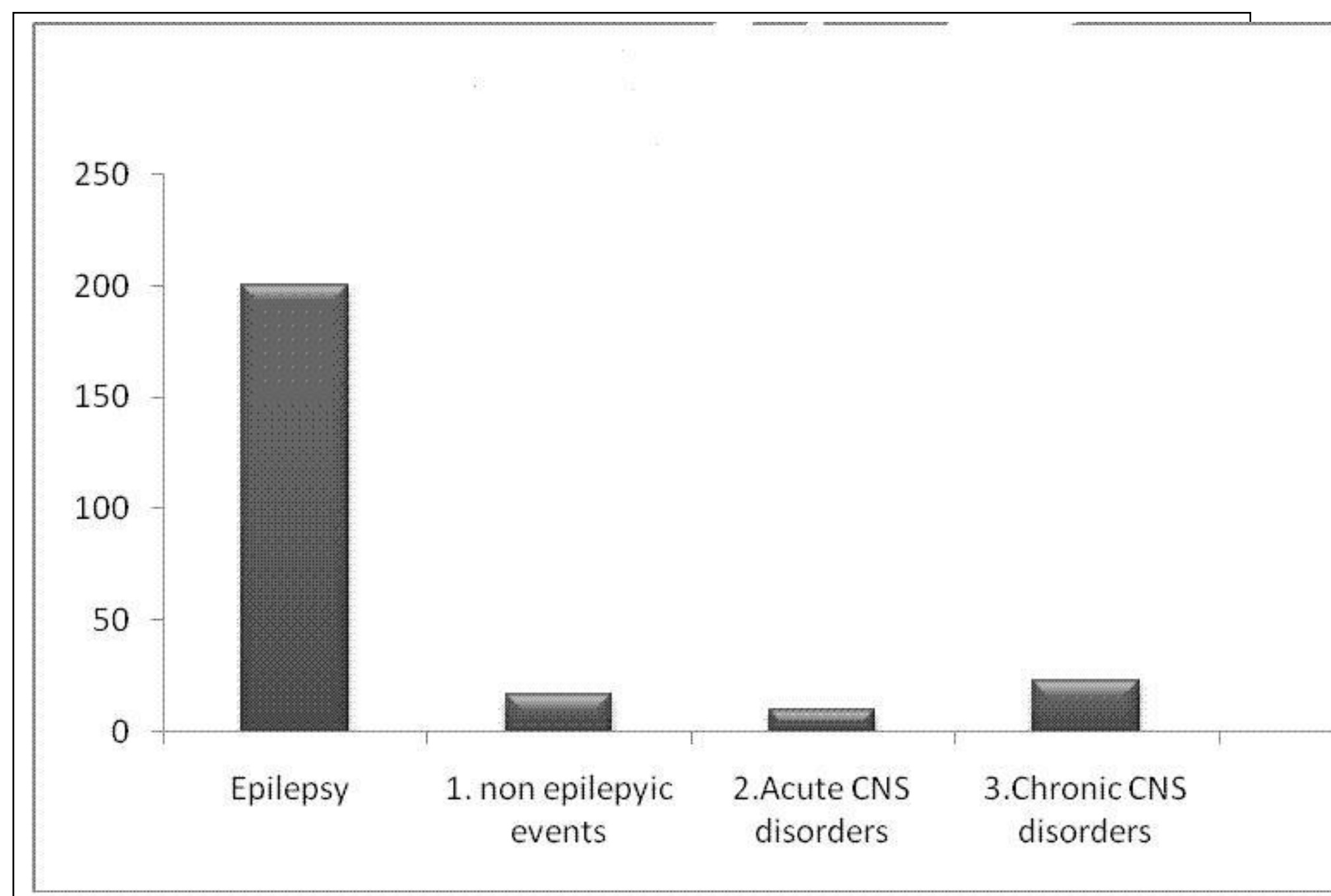

Figure 1 : Reasonfor referral electroencephalogram 


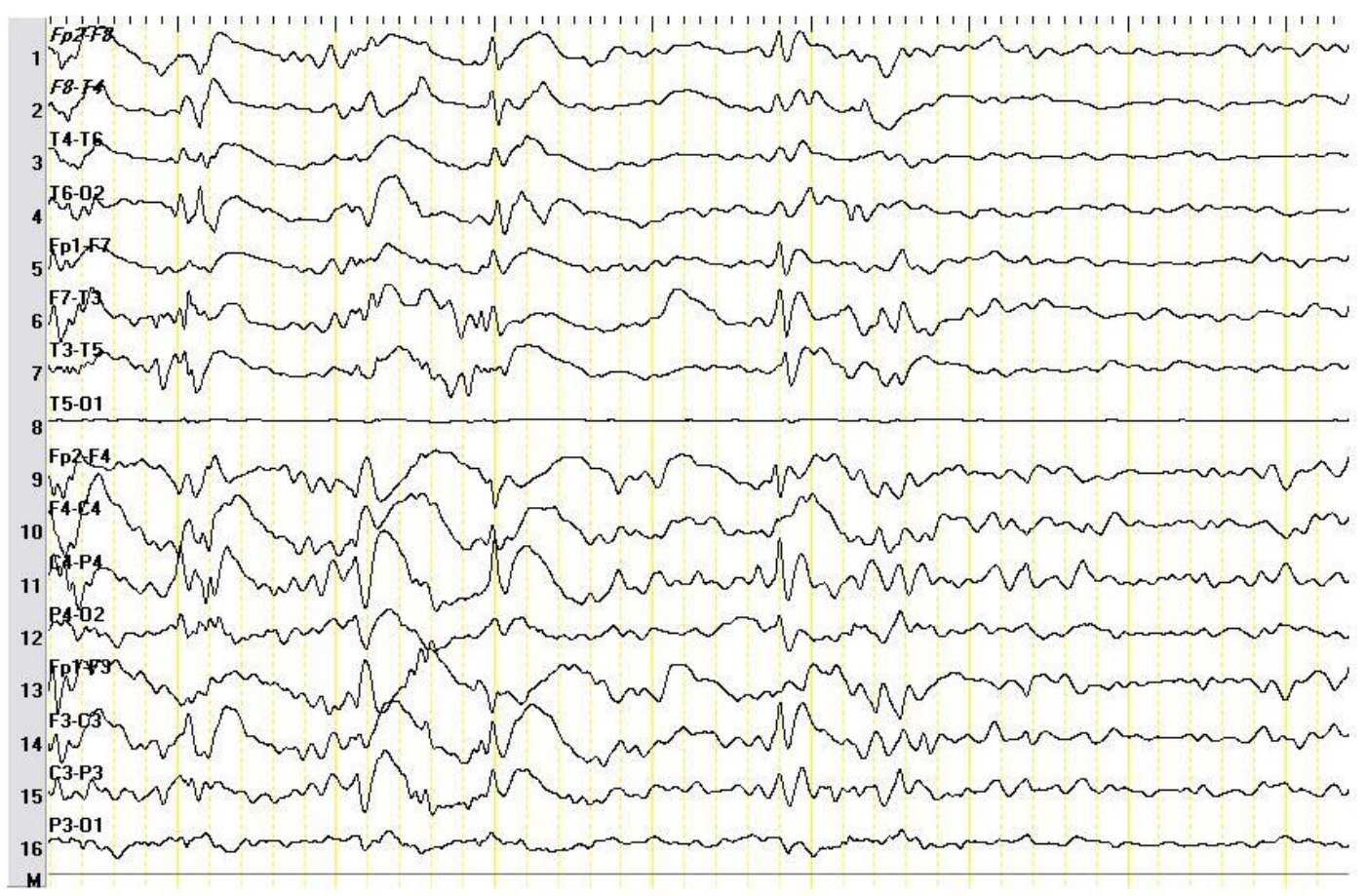

Figure 2 : Electroencephalography of patient presented with focal epilepsies showed Partial epileptic activity over right side of brain

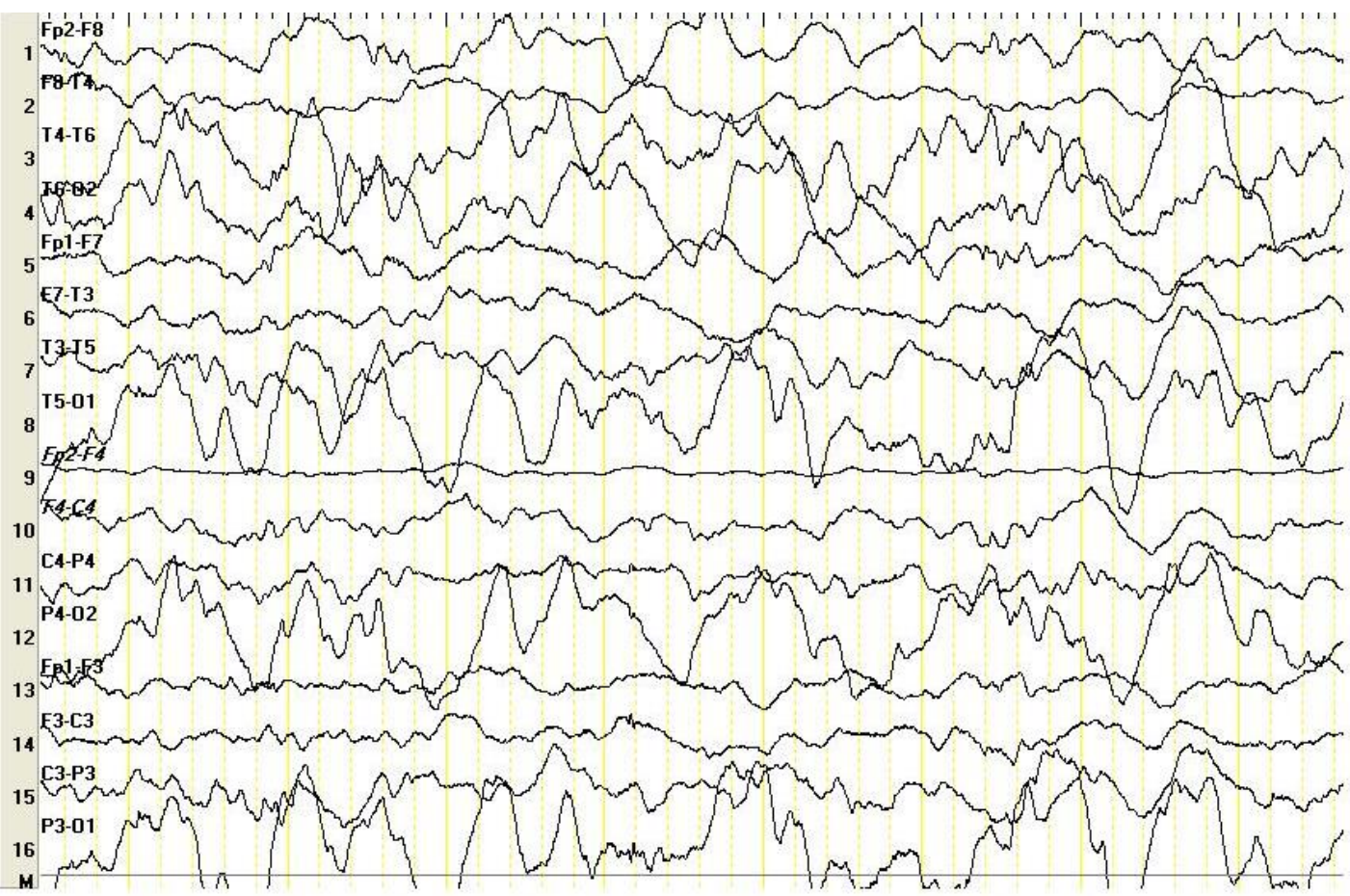

Figure III : Electroencephalography of patients presented with history of consciousness disturbance showed Abnormal background suggestive of encephalopathy process 


\section{Reference}

Adrian Jf\& Colin DB( 2000). Uses and Abuses of the EEG in Epilepsy . epilepsia , 41(3):S10-S18, Airoldi L, Beghi E, Bogliun, Crespi V \& Frattola (1999 ).Rational use of EEG in adults in clinical practice. Journal of Clinical Neurophysiology ,16(5):456-61

Ajmone M C\& Zivin LS(1970). Factors related to the occurrence of typical paroxysmal abnormalities in the EEG records of epileptic patients. Epilepsia , 11(4):361-81

Barron (1991) .The child with spells. Pediatric Clinics of North America , 38(3):711-24

Binnie CD (1994 ).Prior PF. Electroencephalography. J Neurol Neurosurg Psychiatry, 57(11):1308-19

Binnie CD(1996).Epilepsy in adults: diagnostic EEG investigation. In: Kimura J, Shibasaki H, eds. Recent advances in clinical neuro- physiofogy. Amsterdam: Elsevier, :217-22

Blume WT. \& Kaibara(1999) .Role of the electroencephalogram in some pediatric neurological problems. In: Atlas of Pediatric Electroencephalography (Eds W. T. Blume and M.

Kaibara). Philadelphia, Lippincott Raven,: pp. 361371.

Camfield PR, Gordon K, Camfield CS, et al(1995). EEG results are rarely the same if repeated within six months in childhood epilepsy. Can J Neurol Sci ., 22(4):297-300

Dalby MA(1969). Epilepsy and three per second spike and wave rhythms. A clinical and electroencephalographic and prognostic analysis of 346 patients. Acta Neurologica Scandinavica , 45 ( $40): 1-180$

Donat JF \&Wright(1990).Episodic symptoms mistaken for seizures in the neurologically impaired child. Neurology Neurology,40(1):156-7.

Falope ZF, Ogunniyi A, Osuntokun BO(1993 ).Factors associated with epileptiform EEG patterns in Nigerian epileptics. East Afr Med J.,70(5):294-6.

Goldensohn (1997 ). Historical perspectives and future directions. In: Wyllie E. The Treatment of Epilepsy. Baltimore: Williams and Williams, 191203.

Marsan CA \& Zivin LS(1970 ).Factors related to the occurrence of typical paroxysmal abnormalities in the
EEG records of epileptic patients. Epilepsia, 11(4):361-81

Metrick ME, Ritter FJ., Gates JR., Jacobs MP., Skare, SS. and Loewenson RB( 1991 ).Nonepileptic events in childhood. Epilepsia.,32(3):322-8.

Nicolaides P , Appleton RE. and Beirne (1995). EEG requests in paediatrics: an audit. Archives of Disease in Childhood Jun;72(6):522-3.

Niedermeyer (1999).The Normal EEG of the Waking Adult. In: Niedermeyer E, Lopes da Silva FH (eds.), Electroencephalography: Basic Principles, Clinical Applications and Related Fields. Lippincott Williams \& Wilkins, Baltimore, pp. 149-173

Noachtar S, Binnie C, Ebersole J, Mauguière F, Sakamoto A, Westmoreland BA (1999)glossary of terms most commonly used by clinical electroencephalographers and proposal for the report form for the EEG findings. The International Federation of Clinical Neurophysiology .Electroencephalogr Clin Neurophysiol Suppl. ;52:2141.

Petersen I, Eeg-Olofsson O, Sellden (1968). Paroxysmal activity in EEG of normal children. In: Kellaway P, Petersen I, eds. Clinical Electroencephalography of Children. New York: Grune \& Stratton;: 167-188

Phillips BB, Drake ME, Hietter SA, et al (1993). Electroencephalography in childhood conduct and behavior disorders. Clin Electroencephalogr ,24(1):25-30

Saunders MG\& Westmoreland BF. (1997).The EEG evaluation of disorders affecting the brain diffusely. In: Current Practiceof Clinical Electroencephalography (Eds D. W. Klass and D. D. Day). New York, Raven Press,: pp. 370-371

Small JG(1993). Psychiatric disorders and EEG, in Electroencephalography: Basic Principles, Clinical Applications, and Related Fields, edited by Niedermeyer E, Lopes Da Silva F. Baltimore, Williams and Wilkins, , pp 581-596

Sundaram M, Sadler RM, Young GB. and Pillay(1999). EEG in epilepsy: current perspectives. Canadian Journal of Neurological Sciences ,26(4):255-62.

Van WC, Naylor (1998) .Do we know what inappropriate laboratory utilization is? JAMA .280(6):550-8

Williams J, Schulz EG, Griebel ML (2001).Seizure occurrence in children diagnosed with ADHD. Clin Pediatr (Phila). 40(4):221-4.

Wyllie E, Friedman D , Luders (1991).Outcome ofpsychogenic seizures in children and adolescents compared to adults. Neurology ,41(5):742-4. 


\title{
تخطيط الاماغ الكهربائي في الاضطر ابات العصبية عد الاطفال
}

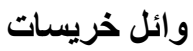 \\ أخصائي أعصاب الأطفال مستشفى الملكة رانيا العبدالله للأطفال / الأردن
}

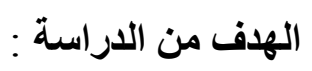

تم اجر اء هذه الدراسة للحصول على المعلومات الأوليه للحالات المرضيه التي تتطلب تخطيط كهربائي التئي

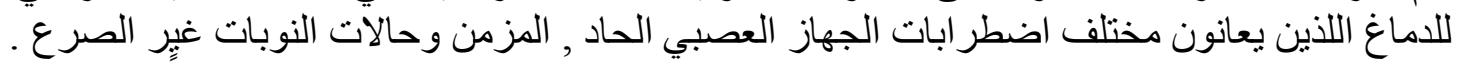

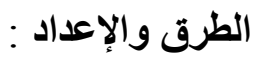

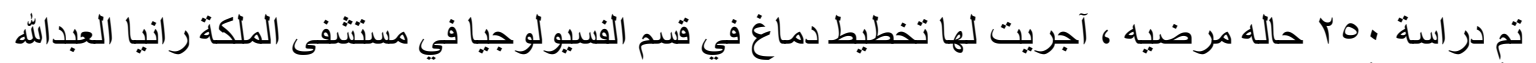

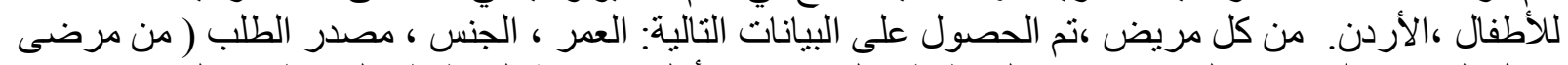

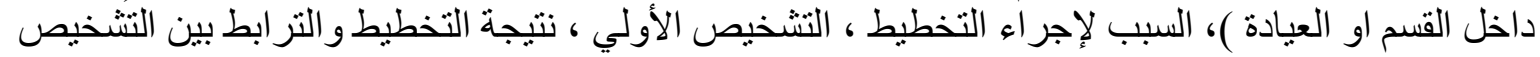
السريري و نتيجة التخطيط.

النتائج :

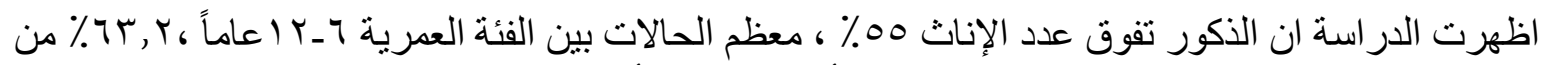

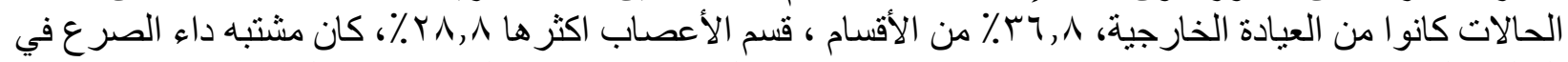

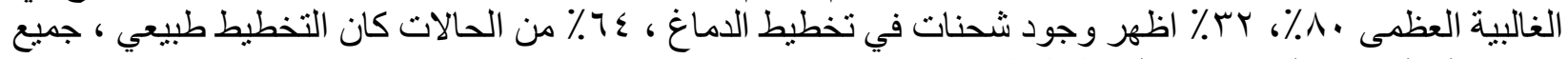
حالات الم الراس والغشي كان التخطيط طبيعي.

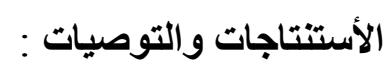

تخلص الدراسة الى ان العديد من طلبات تخطيط الدماغ عند الاطفال كانت غير ضرورية ، يجب ايجاد وسيلة للحد من طلبات تخطيط الدماغ. الكلمات الرئيسة : التخطيط الكهربائي للدماغ، الصرع ، نوبات غير الصرع 